\title{
The influence of sun-protective devices on natural Light distribution in premises
}

\author{
Sergey Stetsky $^{1}$ and Kira Larionova ${ }^{1,{ }^{*}}$ \\ ${ }^{1}$ Moscow State University of Civil Engineering, Yaroslavskoe shosse, 26, Moscow, 129337, Russia
}

\begin{abstract}
The article observes the new approach to a lighting environment in premises of civil buildings in hot and sunny climatic conditions. Under such conditions, the use of sun-protective devices (SPD) of different types and geometrics becomes traditional way of passive climate control in interiors. However, the authors determined, that the most traditional types of external SPD (such as canopies or awnings) have a different effect on indoor lighting environment due to the conditions of external natural illumination under overcast sky vault or clear sky conditions. In the first case, the stationary SPD act as shadowing elements, which block the light flows from the CIE standard overcast sky. In the second case, which corresponds to a clear sky sunny conditions, such SPD block the solar radiation, decreasing overheating and reflect sun beams to an interior, increasing the value of daylight factor (DF) at least in the furthest from windows areas of a premise. The proposed solutions allow reducing electric power consumption in buildings.
\end{abstract}

\section{Introduction}

The problems of indoor comfortable environment conditions design and creation are highly evaluated in the courtiers of near and Middle East. For the time being, such issues are considered in these regions mainly on the basis of natural (passive) methods of indoor climatization. These are architectural and structural methods of design, which correspond to traditional architecture of the region in question [1-10].

The most-widely used means of sun-protection in the considered climatic conditions are sun-protective devices in form of canopies or awnings, vertical ribs, blinds (jalousies) or shutters. In the study described, we consider the outer stationary canopies, which, as we believed, are the mean not only to block the overheating generation of solar radiation but to improve the indoor natural lighting values, too. [10-15].

The studied issues are based on the two main Standard conditions, which, in this article, we tried to upgrade and actualize.

There are two main points, which are considered as a Standard Ones, according to the contemporary Russian and Foreign Codes and regulation on Natural lighting of interiors and insolation. [16-19].

These are:

\footnotetext{
*Corresponding author: LarionovaKO@mgsu.ru
} 
I. The method of DF design, suited for standard overcast sky conditions (C.I.E. overcast sky vault), does not take into account the clear sky sunny conditions, which are the typical for majority of southern regions;

II. According to the Codes and regulations mentioned above, the sun-protective canopies under the standard requirements, are acting mostly as shadowing elements.

But, under a clear sky conditions, they could act as light-reflecting units, improving the lighting environment in the premises in question [22-24].

These assumptions are going to be proved in the studies considered.

\section{Theoretical background}

The important point in the studies in question takes the value of a "q" factor, which takes into account the luminance of a sky, ether overcast or the clear one, and the value of a " $\tau_{4}$ " factor depending on the size of a canopy, and ratio between it's projection and the height from the window sill to the canopy. « $\tau_{4}$ » is a factor, which takes into account the type and size of an external sun protection. These sizes and ratios, in the long run, dictate the value of the angle of observation "Q" from a design point to a sky vault through the geometrical center of a window.

According to $[1,11,22,24]$, the design scheme and the graph of a dependence are as follows (see figure 1). But, at the same time, the "q" values in the cast of a clear sky are much different from the "q" values in the case of standard overcast sky.

Moreover, the former "q" values depend not only on angle of observation but on the orientation of windows, too (see table 1).

Hence, it should be noted that under overcast sky conditions, the smaller the angle "Q", the smaller the value of a "q" factor. And under clear sky condition, the smaller the angle "Q", the bigger the value of a "q" factor.

Taking into account that the smaller angles "Q" correspond to longer distance from a window to design points, one could assume a rise in a "DF" valued in the furthest from a window points of a premise. Thus, the requirements of "Codes and regulations" have a real tendency to be satisfied, as far as the required normative values of a "DF" belong to this area.

If we consider the light flows coming into interior of a premise with external sunprotective devices in form of canopies, as shown on figure 2, the formula to determine "DF" values under system of side natural lighting can be presented as follows:

$$
\mathrm{DF}_{\mathrm{SL}}^{\mathrm{DES}}=\mathrm{DF}_{\mathrm{SUN}}+\mathrm{DF}_{\mathrm{OS}}+\mathrm{DF}_{\mathrm{GS}}+\mathrm{DF}_{1}+\mathrm{DF}_{2}+\mathrm{DF}_{3}
$$

where:

$\mathrm{DF}_{\mathrm{SL}}^{\mathrm{DES}}$ - design daylight factor for side-lit premises external sun-protection;

$\mathrm{DF}_{\mathrm{SUN}}$ - daylight factor from sun flows;

$\mathrm{DF}_{\mathrm{OS}}$ - daylight factor from the overcast sky;

$\mathrm{DF}_{\mathrm{GS}}$ - daylight factor, due to the flows reflected from a ground surface;

$\mathrm{DF}_{1}$ - daylight factor, due to the light reflected from the upper side of SPD;

$\mathrm{DF}_{2}$ - daylight factor, due to the light reflected from the bottom surface of SPD;

$\mathrm{DF}_{3}$ - daylight factor, due to the light reflected from the internal surface of a premise.

In this study, only the light flows reflected from the S.P.D. were taken into account, and the reflection from surface of an adjacent ground in the premises of multistory buildings was negligible.

The portion of a D.F., dependent on the reflected light flows from a canopy, could be calculated with use of the formula 2 , which is the result of numerous scientific researches devoted to a problem considered [12, 18, 24].

The design scheme is presented in figure 3 . 


$$
\mathrm{DF}_{1}=\left[\left(\frac{8,6}{\mathrm{x}}\right)-0,011 \mathrm{x}\right] \cdot \mathrm{H} \cdot \frac{\mathrm{E}_{\mathrm{S}}^{\prime} \cdot \tau_{\mathrm{G}}}{\mathrm{E}_{\mathrm{D}}^{\prime} \cdot \mathrm{K}_{\mathrm{S}}} \cdot \rho_{\mathrm{us}} \cdot \rho_{\mathrm{c}} \cdot \frac{\mathrm{n}_{2}}{100}
$$

where, according to the design scheme on Fig.5:

$\mathrm{x}-\mathrm{a}$ distance of a design points from a window;

$\mathrm{H}-\mathrm{a}$ height of a premise;

$\mathrm{E}_{\mathrm{S}}^{\prime}$ - the design value of a summary natural lighting with respect of shadowing possible;

$\mathrm{E}_{\mathrm{D}}^{/}$- the design value of a diffuse natural lighting with respect of shadowing possible;

$\rho_{\mathrm{us}}$ - the reflection quotient of an upper surface of a canopy;

$\rho_{c}-$ the reflection quotient of a ceiling of a premise;

$\tau_{G}$ - a general factor of the light's penetration through a window;

$\mathrm{K}_{\mathrm{S}}$ - a spare factor;

$\mathrm{n}_{2}$ - a number of light rays passing through a window to a design point, according to the Daniluk graph 2.

A new formula to calculate a DF values under a clear sky conditions was suggested (3). This formula is presented here in a simplified form, which does not take into account the reflective shadowing capacities of a surrounding development:

$$
\mathrm{DF}_{\mathrm{SL}}^{\mathrm{DES}}=\frac{\varepsilon_{\mathrm{SL}}^{\mathrm{CS}} \cdot \mathrm{q}_{\mathrm{CS}} \cdot \tau_{\mathrm{G}} \cdot \mathrm{r}_{\mathrm{G}}^{\mathrm{MOD}}}{\mathrm{K}_{\mathrm{S}}}
$$

where: $\mathrm{DF}_{\mathrm{SL}}^{\mathrm{DES}}$ - daylight factor in a certain design point of a premise with side-lit interior for a clear sky conditions of natural outdoor illumination;

$\varepsilon_{\mathrm{SL}}^{\mathrm{CS}}-$ geometrical quotient of DF for side-lit interiors in the clear sky conditions of a natural illumination.

$\mathrm{q}_{\mathrm{CS}}$ - a quotient, which takes into account the current uniform luminance of a clear sky;

$\tau_{\mathrm{G}}-$ see above;

$\mathrm{K}_{\mathrm{S}}$ - see above;

$\mathrm{r}_{\mathrm{G}}^{\mathrm{MOD}}$ - a general modified factor, which takes into account the reflection of light flows not only from the internal surfaces of a premise but also from the upper surface of an external, lowery-positioned SPD, which can be calculated by the Formula 4:

$$
\mathrm{r}_{\mathrm{G}}^{\mathrm{MOD}}=\mathrm{r}_{\mathrm{G}}^{2}-0,3(\mathrm{l}+\delta)^{2},
$$

where: 1 - a distance from a design points to an external wall;

$\delta$ - the thickness of an external wall;

$\mathrm{r}_{\mathrm{G}}$ - a design factor, which takes into account a rise in DF values to the light flows reflected from the internal surfaces of a premise.

\section{Field and case studies}

The appropriate field studies were carried out by the members of the "Design of Buildings and Structures" chair of the Moscow State university of Civil Engineering and their postgraduates in the apartment of a multistory residential building in Beirut, Lebanon. Originally, the living rooms of the building had no SPD, as far as they were equipped with air-conditioning units. Due to this, we had to use a temporary canopied, made of dry wall panels over the window of a premise under the study and over the window in a room beneath to ensure a reflection of sun rays flow from canopy below in the considered room $[7,8,9,22,23,24]$.

This makes possible to determine a D.F. values under the original case as well as under the experimental case. Moreover, these cases were investigated with clear sky conditions and with diffuse light from a sky vault. The results are shown in Figures 4 and 5. 
Table 1. The values of a of «q» factor for «overcast and, clear sky» conditions of external lighting.

\begin{tabular}{|c|c|c|c|c|c|c|c|}
\hline $\begin{array}{c}\text { The } \\
\text { values of }\end{array}$ & $\begin{array}{c}\text { The values of a of «q» } \\
\text { factor for «CIE } \\
\begin{array}{c}\text { a of «Q» } \\
\text { angle in } \\
\text { overcast sky» lighting }\end{array}\end{array}$ & \multicolumn{6}{|c|}{$\begin{array}{c}\text { The values of a of «q» factor with clear sky conditions } \\
\text { and orientation of windows }\end{array}$} \\
\cline { 3 - 8 } conditions. & $\mathrm{E}, \mathrm{W}$ & $\mathrm{N}$ & $\mathrm{NE}, \mathrm{NW}$ & $\mathrm{SW}$ & $\mathrm{S}$ & $\mathrm{SE}$ \\
\hline 1 & 2 & 3 & 4 & 5 & 6 & 7 & 8 \\
\hline 10 & 0.58 & 0.93 & 0.79 & 1.14 & 1.40 & 1.21 & 0.94 \\
\hline 20 & 0.72 & 0.67 & 0.57 & 0.79 & 1.02 & 0.83 & 0.65 \\
\hline 30 & 0.86 & 0.52 & 0.43 & 0.59 & 0.79 & 0.62 & 0.48 \\
\hline 40 & 0.98 & 0.43 & 0.38 & 0.47 & 0.63 & 0.48 & 0.38 \\
\hline 50 & 1.08 & 0.38 & 0.34 & 0.39 & 0.52 & 0.40 & 0.32 \\
\hline 60 & 1.17 & 0.34 & 0.31 & 0.34 & 0.45 & 0.34 & 0.29 \\
\hline 70 & 1.23 & 0.33 & 0.31 & 0.32 & 0.39 & 0.32 & 0.29 \\
\hline 80 & 1.275 & 0.32 & 0.31 & 0.31 & 0.33 & 0.31 & 0.28 \\
\hline 90 & 1.29 & 0.33 & 0.32 & 0.33 & 0.35 & 0.33 & 0.32 \\
\hline
\end{tabular}

A)

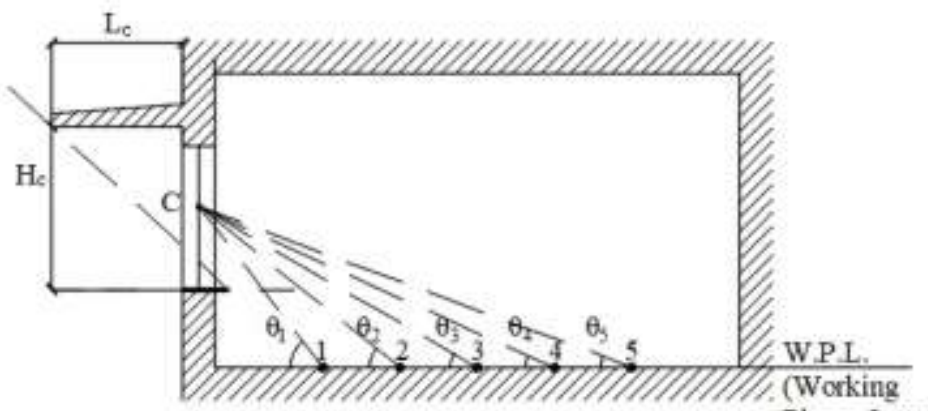

B)

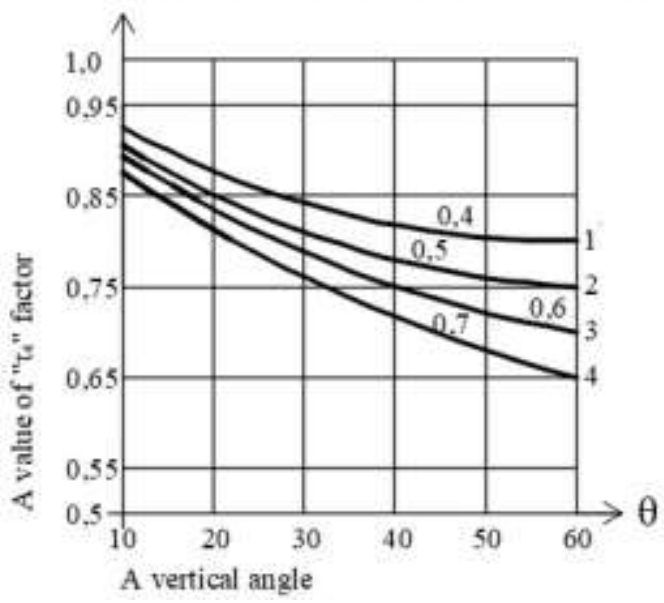

Planes Level)

Fig. 1. The design scheme (A) and graph (B) showing the values of «Q» and « $\tau_{4} »$ for different sizes of external sun-protection canopies. Note: $1,2,3,4$ are curves showing the different « $\tau_{4} »$ values for different ratios of $L_{c}: H_{c}$, the $\langle\mathrm{C} »$ is a central point of a window. 


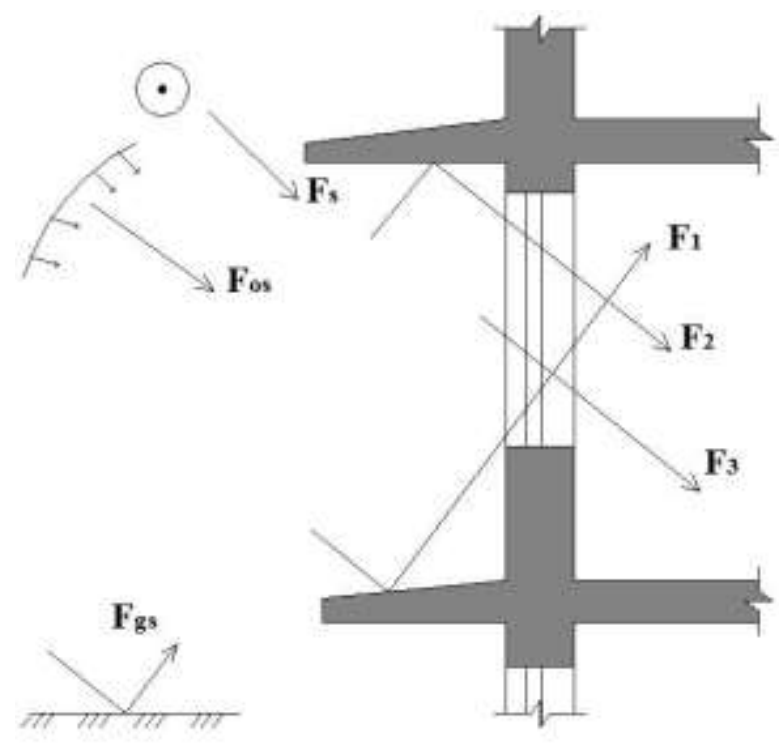

Fig. 2. Light flows coming into interiors with side natural lighting system and implementation horizontal canopies (awnings) as S.P.D. Key: $F_{s}$ - light flow from a sun; $F_{\text {os }}-$ light flow from overcast sky; $F_{g s}$ - light reflected from the ground's surface; $F_{1}$ - light flow from top surface of a canopy; $F_{2}$ light flow from bottom surface of a canopy (awning); $F_{3}$ - light flow penetrating in a premise directly from sun and sky.

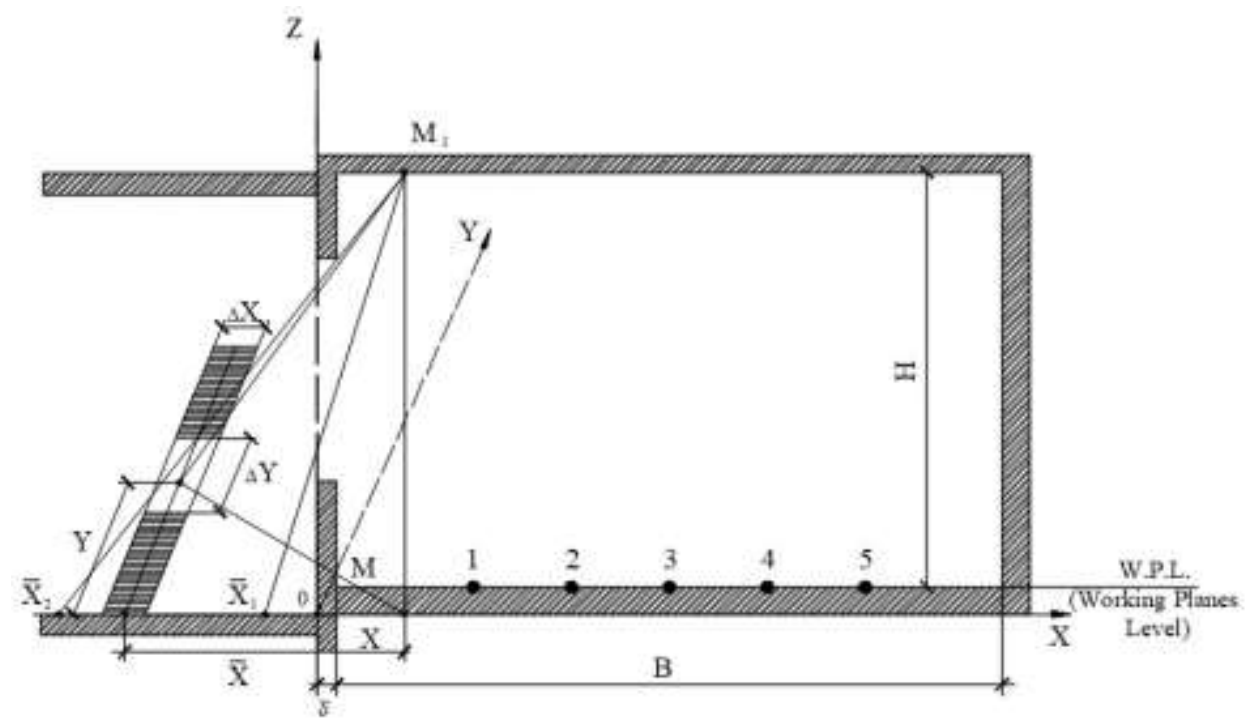

Fig. 3. The design scheme for determination a reflected portion of side natural lighting from external S.P.D. in form of canopy. 


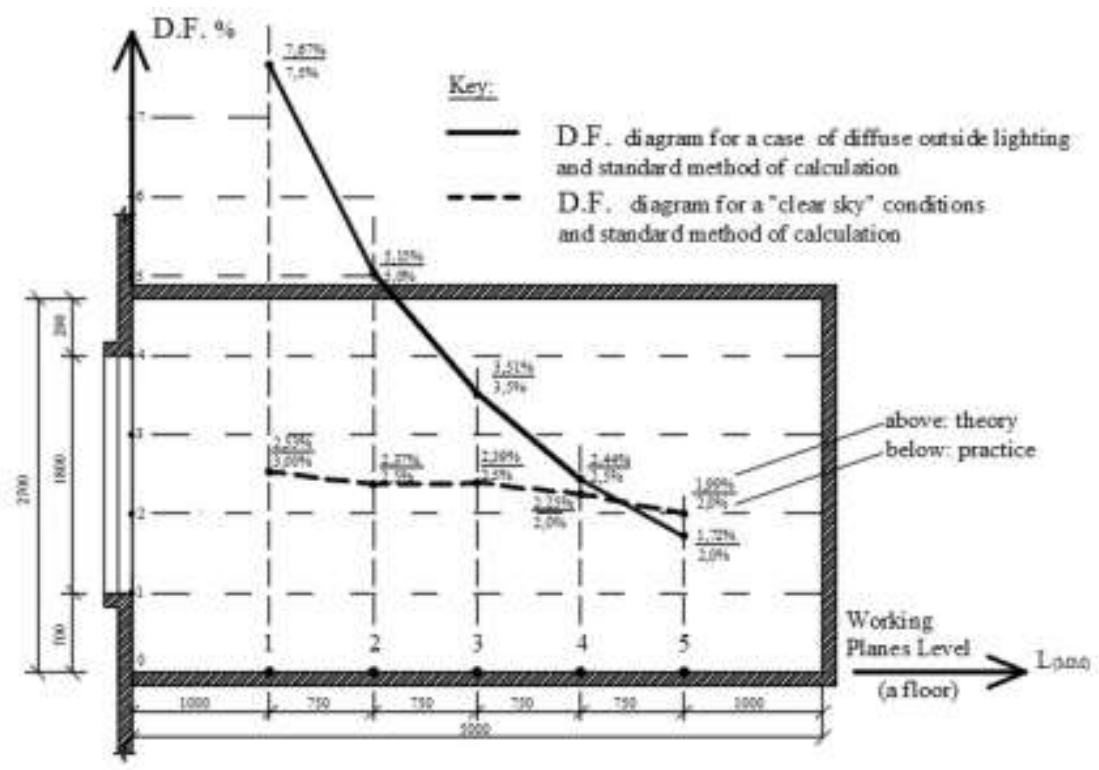

Fig. 4. Daylighting factor diagrams in a premise of a residential building without S.P.D.

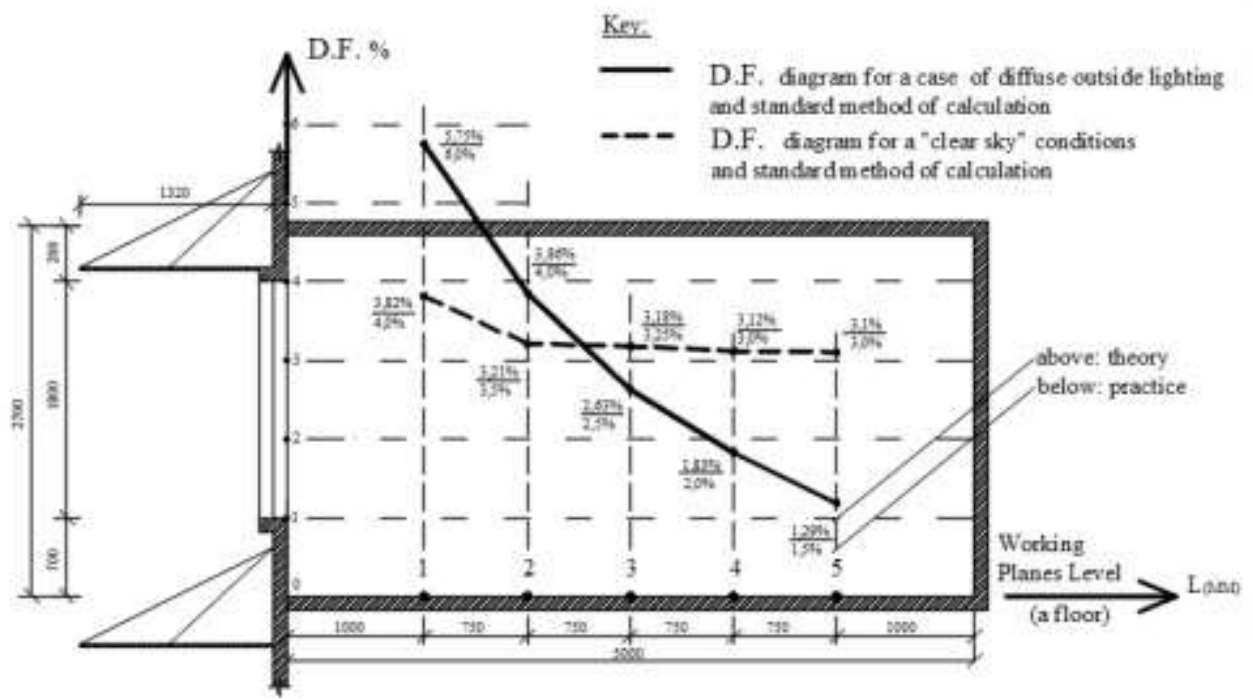

Fig. 5. Daylighting factor diagrams in a premise of a residential building with temporary S.P.D.

\section{Conclusions}

The studies show that:

1. The use of SPD under of standard CIE overcast sky conditions is not logic, these devices don't perform its main function, but, on the contrary, decrease the level of natural lighting in interiors.

2. Due to reflected light flows from SPD, the level of DF increases in interiors in the furthest from windows area of a premise and decreases in zones near windows. But this is 
possible only under the clear sky conditions and with use of a methodical approach and design formulas suggested by the leading foreign and Russian Scientist mentioned in "References".

3. To satisfy such a different approach to D.F. calculations, it is necessary to separate the methodic and scientific approach to a D.F. determination using «Codes and Regulations» used in Russia and in majority of European countries, based on the standard overcast sky approach and the new approach for clear sky conditions, customary for southern sunny regions.

4. Such a scientific approach might be very useful in the field of energy-effective (passive) building design. The use of external SPD not only decreases the heat gains in the interiors but also, as it was proved, increases the amount of indoor natural light. Both these facts act as reasons for saving energy consumption used for artificial lighting of interiors and air conditioning, in other words, these facts act to improve the internal microclimatic environment in premises of civil buildings in conditions of hot and sunny climate of the region under consideration.

\section{References}

1. N.M. Gusev, N.V. Obolensky, N.P. Nikolskaya, The preface to a collection of scientific works of Scientific - Lighting Engineering (Reserch institute of Building Physics (NIISF), Moscow, 1972)

2. J.Yaser Maksud, The creation of comfort conditions of an indoor environment in civil buildings a Near East, A Ph.D. Thesis (Moscow, 2000)

3. N.V. Obolensky, Lighting research aspects of Insolation and sun-protection in building construction, Abstract of the Doctor of Sciences thesis (Moscow, 1983)

4. S.V. Stetsky, Promyshlennoe i grazhdanskoe stroitel'stvo 7, 76-80 (2015)

5. S.V. Stetsky, M.A. Salo, SMOT of XXI century 10, 64-65 (2004)

6. E.L. Harkness, M.L. Menta, Solar radiation control in buildings (Stroyizdat, Moscow, 1984)

7. S.V. Stetsky, H. Amhaz, SMOT of the XXI century 12, $52-53$ (2004)

8. S.V. Stetsky, S. Suliman, SMOT of the XXI century 5, $82-84$ (2005)

9. S.V. Stetsky, V.A. Khodeir, Vestnik MGSU 8, 39-45 (2012)

10. S.V. Stetsky, V.A. Khodeir, Vestnik MGSU 7, 9-15 (2012)

11. N.M. Gusev, Fundamentals of building physics (Stroyizdat, Moscow,1975)

12. A.K. Soloviev, Assessment of lighting environment of industrial premises under clear sky conditions (Svetotechnika, Moscow, 1987)

13. A.K. Soloviev, The physics of the environment (ASV publishing, Moscow, 2008)

14. N.V. Obolensky, Industrial construction 1, 12-14 (1965)

15. S.V. Stetsky, S.A. Porublev, SMOT of the XXI century 4, 34 -37 (2011)

16. Russian Federation Standard SP 52.13330.2011

17. Russian Federation Standard SanPin 2.2.1/2.1.1.1076

18. Solar shading for low-energy buildings (European Solar-Shading Organization, Belgium, 2012)

19. Understanding overheating - where to start (an introduction for house builders and designers) (NHBC foundation, Great Britain, 2012) 